\title{
DIREITO FUNDAMENTAL SOCIAL À PREVIDÊNCIA SOCIAL E O DEVER DE (IN)APLICABILIDADE DA RESERVA DO POSSÍVEL: UMA VISÃO NO ACORDO DA AÇÃO CIVIL PÚBLICAN 0002320-59.2012.4.03.6183
}

\author{
FUNDAMENTAL SOCIAL RIGHT TO SOCIAL SECURITY AND THE DUTY \\ (IN)APPLICABILITY OF RESERVE FOR POSSIBLE:A LOOK INTO THE AGREEMENT OF \\ PUBLIC CIVIL ACTION N ${ }^{o}$ 0002320-59.2012.4.03.6183
}

Franchesco Maraschin Freitas

Mestrando em Direito pela Faculdade Meridional - IMED - bolsista CAPES. É advogado autônomo com ênfase em Direito Previdenciário e Direito Civil. Membro da Rede Brasileira Direito e Literatura (RDL). E-mail: freitas.franchesco@gmail.com

Jaqueline Mielke Silva Doutorado em Direito pela Universidade do Vale do Rio dos Sinos - UNISINOS Professora Pesquisadora da Faculdade Meridional (IMED), Professora Pesquisadora da Faculdade Inedi - Cesuca e Professora em cursos de Especialização em diversas instituições de ensino superior. E-mail: jaqueline@mielkelucena.com.br

Recebido em: 02.07.2015

Aprovado em: 15.02.2016

DOI: $10.5585 / \mathrm{rdb} . \mathrm{v} 12 \mathrm{i} 5.274$

SUMÁRIO: Introdução. 1 Previdência como Direito Social na Constituição Federal de 1988. 2O acordo na Ação Civil Pública $\mathrm{n}^{\circ}$ 000232059.2012.4.03.6183. 3.Garantia dos benefícios previdenciários versus a reserva do possível. Considerações finais. Referências.

\section{RESUMO}

Os benefícios previdenciários são considerados direitos fundamentais sociais, como contempla a Constituição Federal. Esses direitos são fundamentais ao ponto de que é impossível alcançar a efetividade de uma vida digna sem o resguardo de uma previdência consolidada e garantidora do seu cumprimento legal. A reserva do possível não pode ser alegada quando o objeto do embate se tratar de prestações previdenciárias devidas pela autarquia federal, haja vista o núcleo alimentar do benefício. A ação civil pública $\mathrm{n}^{\circ}$ 0002320-59.2012.4.03.6183 trouxe consigo uma questão relevante na discussão de direitos sociais e o dever do Estado na efetivação imediata desses quando analisamos sob o pálio do utilitarismo.

Palavras-chaves: Direitos Sociais.Reserva do Possível.Previdência Social.Ação Civil Pública. 


\begin{abstract}
Social security benefits are considered fundamental social rights, contemplates as the Federal Constitution. These rights are fundamental to the point that it is impossible to achieve the effectiveness of a dignified life without the guard of a consolidated security and guarantor of their legal compliance. The reserve for possible can not be claimed when the reason of the clash is social security benefits payable by the independent federal agency, considering the nucleus sustenance of the benefit. The Public Civil Action $\mathrm{n}^{\circ}$ 0002320-59.2012.4.03.6183 brought with it a relevant question in the discussion about social rights and the State's duty in the immediate effectuation of these when we look under the cover of utilitarianism.
\end{abstract}

Keywords: Social Law.Reserve for Possible. Social Security. Public Civil Action.

\title{
INTRODUÇÃO
}

A Constituição Federal de 1988 surge como resultado da insatisfação dos cidadãos com o regime militar e o desprezo com a Dignidade da Pessoa Humana. Na concepção de Wagner Balera (2000, p. 32), nossa Carta Republicana instituiu um autêntico Sistema de Seguridade Social. Dentro de um contexto no qual o trabalho é a essência da ordem social, a Seguridade Social seria o núcleo para o desenvolvimento e manutenção da Dignidade da Pessoa Humana, sendo-lhe concedida a tarefa hercúlea de assegurar a todos um mínimo existencial nas situações capazes de gerar necessidades sociais.

O Direito Fundamental Social à Previdência Social foi acolhido como tal por nossa Carta Magna dada a consonância com a tendência internacional de reconhecimento da sua valorização, visto que em seu $\S 2^{\circ}$ do artigo $5^{\circ}$ há o acolhimento dos direitos materialmente fundamentais que decorrem dos tratados internacionais em que o Brasil é signatário, como é o caso da Declaração Universal dos Direitos do Homem, em seu artigo 22, e a Declaração Americana dos Direitos e Deveres do Homem em seu artigo XVI.

Na tarefa de evidenciar a importância existente na concretização dos Direitos à Previdência Social, e efetuar uma crítica quando botado à prova sua concretização perante a reserva do possível e os limites orçamentários, foi necessária a análise do acordo firmado entre Ministério Público Federal, Sindicato Nacional dos Aposentados, Pensionistas e Idosos da Força Sindical e Instituto Nacional de Seguro Social na Ação 
Civil Pública $\mathrm{n}^{\mathrm{o}}$ 0002320-59.2012.4.03.6183 que tem como objeto o pagamento fracionado, por índices cronológicos e de valores, da revisão devida.

Na presente Ação Civil Pública foi discutido o dever do Instituto Nacional de Seguro Social (INSS) de proceder à revisão dos benefícios de auxílio-doença, aposentaria por invalidez e pensões deles decorrentes que foram calculados com base em todos os salários-de-contribuição integrante do período básico de cálculo, por força do que fora estipulado no Decreto 3.265/99, solicitando o restabelecimento do percentual inicialmente fixado pela Lei 9.876/99, isto é, $80 \%$, desde a competência 07/1994 até a competência anterior a data de entrada do requerimento administrativo junto ao INSS, excluindo os já revistos e os atingidos pela decadência. O principal motivo para formulação do acordo é o grande impacto econômico que ocorrerá aos cofres da Previdência ao final de todas as revisões.

O trabalho desenvolvido, sobre a condução metodológica da fenomenologia hermenêutica, concentrando-se na pesquisa bibliográfica e empírica, estando dividindo em três seções: no primeiro capítulo é feita uma releitura histórico-constitucional da Previdência Social como um Direito Fundamental Social; no segundo capítulo é apresentado o objeto e a fundamentação do acordo na Ação Civil Pública nº 000232059.2012.4.03.6183 e; no terceiro capítulo é analisado o (não) dever de enquadramento dos benefícios previdenciários na política de reserva do possível.No presente estudo são apresentados os fundamentos teóricos, a partir do caso prático, sobre a suma importância do Direito Fundamental Social à Previdência Social e, ademais, os motivos da importante quebra do paradigma da ética utilitarista frente os direitos previdenciários.

\section{Previdência como Direito Social na Constituição Federal de 1988}

A previdência social, como parte intrínseca da seguridade social, é um sistema que se encontra, a partir de 1988, originalmente em sede constitucional. A segurança social passou a ser segurança normativa, ou melhor, passou a ser segurança normativaconstitucional (CORREIA, 2013, p. 1902-1907). Todavia, não haveria essa segurança se o valor do benefício fosse um valor exíguo ou pior, se não houvesse uma relação de benefício.

$O$ conceito de previdência social não está implícito no artigo $6^{\circ}$ da atual Constituição Federal, contudo, remete-se a ideia de que toda forma de compreender os 
direitos fundamentais individuais deve ser instrumentada pelos direitos fundamentais sociais. Dessa forma, como bem defende o Supremo Tribunal Federal, em decisão que foi relatada pelo Ministro Sidnei Sanches, os direitos fundamentais individuais do artigo $5^{\circ}$ permeiam a Constituição por completa, sendo assim, obviamente, que o mesmo ocorreria com os direitos fundamentais sociais, cujos não estão apenas no artigo $6^{\circ}$, mas se encontrariam também, por exemplo, no artigo 201, que prevê elementos mínimos de previdência social (CORREIA, 2013, p. 1908).

\subsection{Concepção dos Direitos Sociais na Constituição de 1988}

O Brasil adotou em seu ordenamento os direitos sociais a partir da Constituição de 1934, de forma indireta, garantindo, por exemplo, a educação como "direito de todos", em seu artigo 149, estipulando os preceitos de natureza trabalhista, médicoassistencial e previdenciária em seu artigo 121, §1. Após, na Constituição de 1937 outorgada por Getúlio Vargas, foi introduzido o capítulo designado de "Ordem Econômica", em que seu artigo 136 dispõe que "o trabalho é um dever social" e que o Estado possui o dever de protegê-lo, "assegurando-lhe condições favoráveis e meio de defesa”. Só após, na Constituição de 1946, que houve a designação de um título constitucional com a nomenclatura "Da Ordem Econômica e Social".

Já na Constituição de 1967, as normas que antes eram vistas apenas como preceitos direcionados aos legisladores ordinários passaram a abrigar direitos de natureza constitucional. Mas foi na atual Constituição que houve um salto qualitativo e quantitativo de extraordinário significado no terreno dos direitos sociais ao incluí-los no rol dos fundamentas - sendo, pois, créditos à mobilização social que tanto lutou para sua concretização.

$\mathrm{O}$ adjetivo social que denomina uma das fases do Estado não possui características específicas de relação com o sentido de "coletividade" dos direitos contraposto com "individualidade" ou "sentido privado", mas, antes de tudo, possui um sentido político, ou seja, um comprometimento estatal para sanar as mazelas oriundas das questões sociais. Guarda relação com a evolução do Estado de Direito liberal para um Estado de Direito social. Uma questão de "evolução geracional" dos direitos fundamentais (SARLET, 2013, p. 533-548).

O texto do artigo $6^{\circ}$ da Carta Magna possui um conteúdo genérico e amplo, em que suas definições e objeções são desenvolvidas no decorrer da Carta e também na 
legislação extraconstitucional. Além dessas caracterizações, o citado artigo também se insere num contexto normativo-constitucional mais amplo, bem como define Ingo Sarlet: "O Preâmbulo já evidencia o forte compromisso da Constituição e do Estado com a justiça social, comprometimento este reforçado pelos princípios fundamentais positivados no Título I da CF, dentre os quais se destaca a dignidade da pessoa humana (art. 1 ${ }^{\circ}$, III), positivada como fundamento do próprio Estado Democrático de Direito" (SARLET, 2013, p. 533-548).

Além disso, vale destacar que tal princípio serve como parâmetro para os mais diversos tipos de Direitos Fundamentais, reforçando a complementariedade existente entre direitos individuais (direitos de liberdade) e direitos sociais (direitos de igualdade), na medida em todos eles abrangem parcelas do conteúdo do princípio da dignidade humana, ainda que a ela não se reduzam.

Para Jorge Novais (2010, p. 21), não deve haver a dicotomia entre direitos de liberdade/direitos sociais visto que não se trata apenas de superação do Estado liberal pelo Estado Social, mas sim um acolhimento do primeiro pelo segundo. Essa análise é fundamentada partindo do ponto que há direitos de liberdade e direitos sociais dentro do Estado liberal e os dois tipos no Estado social. Por exemplo, os direitos de voto e de greve são considerados direitos de liberdade, apesar de serem reconhecidos apenas no surgimento do Estado social; e da mesma forma que os direitos de assistência à saúde e à educação serem elementarmente direitos sociais, mesmo que nasceram no Estado liberal.

Na concepção de Eurico Bitencourt Neto (2010, p. 115), os direitos sociais são advindos, necessariamente, dos princípios da dignidade da pessoa humana, da igualdade material e da solidariedade social, cujos formam o modelo de Estado difundido em nosso tempo: o Estado de Direito democrático e social. Dessa concepção ele decorre três consequências principais para que todo Ser humano tenha sua dignidade protegida:

a) a posição do Estado como primeiro garante do respeito e da proteção da dignidade humana; b) a necessidade de que se utilizem critérios de discriminação positiva, a fim de que todos possam ter meios mínimos de defesa e proteção de sua dignidade; c) a utilização de políticas que introduzam e prestigiem os valores da solidariedade social (BITENCOURT NETO, 2010, p. 115).

Ressalta-se, como dito alhures, que os direitos sociais somente podem ser compreendidos a partir da análise conjunta e sistemática de todas as normas 
constitucionais a eles vinculados, bem como da legislação extraconstitucional e jurisprudência.

O reconhecimento dessa sistemática das normas constitucionais - em que há o reconhecimento de direitos implícitos e dispersos do texto constitucional -, faz com que as normas consagradoras de direitos sociais possuam aplicabilidade direta e eficácia imediata, mesmo que essa eficácia deva ser avaliada no contexto de cada direito social e à luz de outros direitos e princípios.

Na generalidade, todos são titulares de Direitos Sociais, vigendo o princípio da universalidade. Contudo, há exceções como, por exemplo, o caso dos direitos dos trabalhadores, a limitação da gratuidade da justiça, as aposentadorias (tempo de contribuição, aposentadoria especial, aposentadoria por idade e por invalidez), os auxílios por incapacidade (doença e acidentário), os salários (família e maternidade) e os benefícios devidos aos dependentes (pensão por morte e auxílio-reclusão), cujos possuem limitações em decorrência de condicionamentos fáticos e jurídicos contrapostos à sua eficácia.

\subsection{Direito social à previdência social}

O Sistema de Seguridade Social, em seu conjunto, como dito alhures, visa a garantir que o cidadão se sinta seguro e protegido ao longo de sua vivência, tendo por fundamento a solidariedade humana. Ela é um dos instrumentos através do qual se pretende alcançar os objetivos fundamentais da República Federativa do Brasil arrolados no artigo $3^{\circ}$ da Constituição. A expressão Seguridade Social, pode ser considerado um termo genérico utilizado por nosso legislador constituinte para designar o sistema de proteção que abrange os três programas sociais de maior relevância: a previdência, a saúde e a assistência social (ROCHA; BALTAZAR JUNIOR, 2012, p. 27).

José AntonioSavaris (2011, p. 25) diferencia a Previdência Social de Seguridade Social: "o sistema pelo qual o Estado e a sociedade protegem o indivíduo contra riscos que podem prejudicar sua saúde, impedir seu desenvolvimento ou diminuir sua capacidade para o trabalho é o que a Constituição Federal de 1988 chama de 'Seguridade Social'. Ela se destina a assegurar os direitos individuais à saúde, assistência social e previdência social". Cada uma destas áreas, atualmente, tem a sua política elaborada por um Ministério específico. 
Para o desenvolvimento do trabalho, frisa-se o que a Declaração Universal dos Direitos do Homem, em seu artigo $25^{\circ}$, preconiza, qual seja que:

Toda a pessoa tem direito a um nível de vida suficiente para lhe assegurar e à sua família a saúde e o bem-estar, principalmente quanto à alimentação, ao vestuário, ao alojamento, à assistência médica e ainda quanto aos serviços sociais necessários, e tem direito à segurança no desemprego, na doença, na invalidez, na viuvez, na velhice ou noutros casos de perda de meios de subsistência por circunstâncias independentes da sua vontade ${ }^{1}$.

A Previdência Social - espécie notoriamente contributiva do gênero seguridade social, não se prescinde da necessária participação econômica do segurado, sem o qual o sistema não seria viável -, como defendida no artigo $6^{\circ}$ da Constituição Federal, é um direito social, ou seja, é um direito constitucional. Um direito social fundamental do indivíduo. Ademais, além de um Direito Fundamental Social escudado em nossa Carta Magna, ele também preconiza a Declaração Americana dos Direitos e Deveres do Homem em seu artigo XVI:

Artigo XVI. Toda pessoa tem direito à previdência social de modo a ficar protegida contra as consequências do desemprego, da velhice e da incapacidade que, provenientes de qualquer causa alheia à sua vontade, a impossibilitem física ou mentalmente de obter meios de subsistência ${ }^{2}$.

Como o sistema é obrigatório, contributivo e solidário - daí a razão da previdência não ser um sistema de característica universal, mas apenas dos grupos que nela se enquadram -, o seu principal alicerce é o princípio da solidariedade social entre os segurados e seus dependentes, ou seja, todos assumem riscos perante o individual. No Brasil, o regime de previdência adotado se baseia no sistema de "repartição simples", caracterizando-se pela transferência de renda entre indivíduos da mesma geração, com os trabalhadores ativos e inativos. Nas palavras de Daniel Machado da Rocha e José Paulo Baltazar Junior (2012, p. 29):

A previdência social no Brasil compreende duas ordens de regimes: os regimes públicos obrigatórios e os regimes complementares de caráter facultativo (art. 202 da CF/88). Nos regimes públicos situam-se o regime geral e os regimes próprios de previdência constituídos pela União, pelos Estados e pelos Municípios para os seus servidores ocupantes de cargos efetivos (D. 3.048/99, art. $6^{\circ}$ ). O regime geral é regulado pela Lei 8.213/91,

\footnotetext{
1 Declaração Universal dos Direitos Humanos. Disponível em <http://www.ohchr.org/EN/UDHR/Documents/UDHR Translations/por.pdf>. Acesso em 03/05/2015.

2 Declaração Americana de Direitos e Deveres do Homem. Disponível em: <http://www.cidh.oas.org/basicos/portugues/b.Declaracao_Americana.htm > Acesso em 03/05/2015.
} 
sendo responsável pela sua concretização a autarquia federal denominada Instituto nacional do Seguro Social - INSS, vinculado ao Ministério da Previdência Social e instituído pelo já referido D. 99.350/90, conforme autorização contida na Lei 8.029/90.

Um cidadão que está inserido no seio da sociedade, em regra, está em razão de sua capacidade de produção e sua força de trabalho. Desta maneira, ocorrendo alguma circunstância que o deixe num momento de vulnerabilidade, ou seja, incapaz de manter seu sustento e de sua família, a Previdência Social revele sua verdadeira importância. É, nas palavras de Cesar Augusto Kato e Rose Kampa (2011, p, 71), "o caráter contributivo e obrigatório da Previdência Social que traduz na expectativa legítima do trabalhador de ser amparado no momento de uma necessidade, interessando especialmente as hipóteses de incapacidade laborativa". Ou seja, traduz a tranquilidade, sobretudo no futuro, como forma de garantia do Ser humano contra o perigo de passar privações, propiciando a efetivação da justiça social.

Corrobora Fabio Lopes Vilela Berbel(2005, p. 122)quando afirma que se trata de um "conjunto de regras e princípios estruturalmente alocados, com escopo de realizar a Seguridade Social que, a partir de uma visão meramente política, seria a proteção plena do indivíduo frente aos infortúnios da vida capazes de leva-lo à indigência, ou seja, a proteção social da infelicidade individual”.

Apesar das normas de direitos sociais exercerem funções jurídico-objetivas no ordenamento constitucional e possuírem eficácia que se origina diretamente da Constituição o seu significado seria restrito caso não houvesse outras normas constitucionais ou infraconstitucionais voltadas à sua concreção (LEDUR, 2009, p, 83). Via de regra, os direitos fundamentais sociais, enquanto gerais (frisa-se os genéricos elencados no artigo $6^{\circ}$ da Constituição), não conferem direito subjetivo, ou seja, por não serem direitos de defesa cuja força eficacial se extrai diretamente da Constituição, fora as exceções alhures, não originam pretensão exercitável em juízo.

Destarte, o que se verifica é que a categorização geral dos direitos sociais como direitos fundamentais não esgota a função e o propósito que a dogmática jurídicoconstitucional se propõe. Contudo, caso não haja nenhuma intervenção estatal de cunho infraconstitucional para proteção e consagração desses direitos sociais objetivos, a própria Carta Magna contempla remédios constitucionais voltados à sua realização, sendo eles o mandado de segurança (individual e coletivo) e a ação popular (artigo $5^{\circ}$, LXX e LXXIII), bem como a ação civil pública (artigo 129, III). 
No caso da Previdência Social, a legislação extravagante (Lei 8.212/91 - Lei que regula a Seguridade Social e seu custeio -, e Lei 8.213/91 - Lei que regula os benefícios da Previdência Social) e a própria carta constitucional (artigo 201 e 202) direcionam a generalidade do artigo $6^{\circ}$ para um caminho de proteção e concretização da esfera previdenciária fazendo com que sejam implementadas políticas governamentais específicas para o seu firmamento.

Sendo assim, é justamente quando a força laboral do cidadão está deficitária, que a Previdência Social ratifica seu papel nuclear, na busca da manutenção do ser humana dentro de um padrão de vida minimamente adequado.

Do exposto, não há dúvidas quanto o reconhecimento à Previdência Social como um Direito Fundamental Social possibilitando a exigência deaplicabilidade imediata nas situações de direito substancial carecedoras de tutela jurisdicional. Contudo, há situações em que a jusfundamentabilidade do Direito Fundamental Social a Previdência Social é ceifada por políticas de contenção financeira e orçamentária, tendo como consequência a usurpação da Dignidade da Pessoa Humana.

\section{O acordo na Ação Civil Pública n ${ }^{0}$ 0002320-59.2012.4.03.6183}

$\mathrm{Na}$ Ação Civil Pública $\mathrm{n}^{\circ}$ 0002320-59.2012.4.03.6183, ajuizada pelo Ministério Público Federal (MPF) e pelo Sindicato Nacional dos Aposentados, Pensionistas e Idosos da Força Sindical (SINDNAPI),quetramitou perante a $2^{\text {a }}$ Vara Previdenciária da Subseção Judiciária de São Paulo/SP, foi discutido o dever do Instituto Nacional de Seguro Social (INSS) de proceder à revisão dos benefícios de auxílio-doença, aposentaria por invalidez e pensões deles decorrentes que foram calculados com base em todos os salários-de-contribuição integrante do período básico de cálculo, por força do que fora estipulado no Decreto 3.265/99, solicitando o restabelecimento do percentual inicialmente fixado pela Lei 9.876/99, isto é, 80\%,desde a competência 07/1994 até a competência anterior a data de entrada do requerimento administrativo junto ao INSS, excluindo os já revistos e os atingidos pela decadência.

Com o fito de por fim à lide, garantir à segurança jurídica e prezar pela organização financeira da autarquia, as partes estabeleceram um acordo para garantir a revisão dos benefícios elegíveis ainda não corrigidos administrativamente e sobre os quais não se tenha operado a decadência, a partir da competência de janeiro de 2013, com pagamento da mensalidade revista a partir de 2013. O pagamento darenda mensal 
revista dos benefícios em fruição e a pagar as diferenças pretéritas em diferentesdatas, conforme o calendário abaixo ${ }^{3}$ :

a) Quantos aos benefícios ativos:

\begin{tabular}{|c|l|c|}
\hline \multicolumn{1}{|c|}{ Idade } & \multicolumn{1}{|c|}{ Valores } & Data Pagamento \\
\hline 60 anos ou mais & Todos os valores & Fevereiro de 2013 \\
\hline De 46 a 59 anos & Até R\$ 6.000,00 & Abril de 2014 \\
\hline De 46 a 59 anos & De R \$ 6.000,00 a R\$ 19.000,00 & Abril de 2015 \\
\hline De 46 a 59 anos & Acima de 19.000,00 & Abril de 2016 \\
\hline Até 45 anos & Até $\mathrm{R} \$ 6.000,00$ & Abril de 2016 \\
\hline Até 45 anos & De $\mathrm{R} \$ 6.000,00$ a $\mathrm{R} \$ 15.000,00$ & Abril de 2017 \\
\hline Até 45 anos & Acima de $\mathrm{R} \$ 15.000,00$ & Abril de 2018 \\
\hline
\end{tabular}

b) Quantos aos benefícios cessados e suspensos:

\begin{tabular}{|c|l|c|}
\hline \multicolumn{1}{|c|}{ Idade } & \multicolumn{1}{|c|}{ Valores } & Abril de 2019 \\
\hline 60 anos ou mais & Todos os valores & Abril de 2020 \\
\hline De 46 a 59 anos & Todos os valores & Abril de 2021 \\
\hline Até 45 anos & Até R\$ 6.000,00 & Abril de 2022 \\
\hline Até 45 anos & Acima de 6.000,00 & \\
\hline
\end{tabular}

Um dos principais motivos que precedeu a feitura do reconhecimento e do acordo pelo INSS é o grande impacto econômico que ocorrerá aos cofres da Previdência ao final de todas as revisões. De acordo com o próprio sítio eletrônico da autarquia, a estimativa de gastos mensais com a revisão é de $\mathrm{R} \$ 56$ milhões. Por ano serão gastos em torno de $\mathrm{R} \$ 728$ milhões. Contudo, o impacto maior será no âmbito do pagamento dos valores atrasados, realizados até 2022, cujos valores gastos serão de, aproximadamente, R\$ 7,7 bilhões ${ }^{4}$.

A afirmação sobre o alto valor despendido com a indenização dos valores devidos e não pagos pela autarquia condiz com o expressivo impacto de despesas

\footnotetext{
${ }^{3}$ Ministério da Previdência Social. Disponível em: 〈http://agencia.previdencia.gov.br/e-aps/servico/414〉 . Acesso em 10/05/2015.

${ }^{4}$ Ministério da Previdência Social. Disponível em: <http://www.previdencia.gov.br/noticias/beneficiosinss-fecha-acordo-para-pagamento-de-revisao-de-beneficios-por-incapacidade/>. Acesso em 10/05/2015.
} 
públicas adicionais. A "inesperada" ordem de pagamento poderia afetar o equilíbrio macroeconômico e comprometer a concretização do próprio direito buscado, bem como a efetividade dos programas sociais das áreas de assistência social e saúde. Ou seja, pela fundamentação do acordo, firmado entre o INSS, o MPF e a SINDNAPI, buscou-se atender o maior número de revisões possíveis, sem atingir o equilíbrio financeiro, econômico e atuarial da autarquia.

Dada à descrença que os beneficiários da autarquia reagiram sobre o acordo firmado, inúmeras foram às ações revisionais individuais ajuizadas em todo território nacional. As ações revisionais têm o condão não de reconhecer o direito de revisão, visto que já foram reconhecidos na Ação Civil Pública, mas sim de buscar o pagamento dos valores atrasados. Apesar de todas as alegações impeditivas do INSS, a $2^{\text {a }}$ Turma Recursal de São Paulo, no Processo 00032185820124036317, tendo como Relator o Juiz FederalLeonardo Vietri Alves De Godoi, reconheceu o direito dos beneficiários de buscar, individualmente, o pagamento das parcelas em atraso, com o fundamento de que mesmo que "tenha sido concedidaadministrativamente a revisão no valor do benefício, a açãojudicial tem valia no que tange à condenaçãoao pagamento de atrasados, não havendo falar-se em falta deinteresse processual".

O acordo citado, de caráter utilitarista, implica postergar demasiadamente a realização de umdireito já reconhecido pela própria autarquia, em detrimento do segurado que já foiprejudicado ao ter seu benefício calculado em desconformidade com o que determina a leiprevidenciária e ferindo frontalmente o direito individual previsto no artigo $5^{\circ}$, XXXVI, da Constituição Federal, visto que a lei não prejudicaráo direito adquirido, o ato jurídicoperfeito e a coisa julgada.

\subsection{Breve análise: a prática utilitarista noacordo da Ação Civil Pública nº002320- 59.2012.4.03.6183.}

O núcleo da teoria moral utilitarista condiz com a ideia de que a ação correta é aquela que proporciona o resultado ótimo em termos de maximização do bem ou utilidades. A ênfase, nas palavras de José AntonioSavaris (2011, p. 33), "não se dá na avaliação moral da prática humana, em seu significado intrínseco, mas nas consequências que serão por ela ocasionadas. [...] $\mathrm{O}$ ser humano não agiria racionalmente senão segundo essa regra de ação". 
Para Richard Posner (2010, p. 63), o utilitarismo é uma teoria tanto da moral individual como da justiça social. O homem íntegro é aquele que se preocupa em elevar a soma total da felicidade, já a sociedade justa "é aquela que busca elevar essa soma total a seu valor máximo". O máximo da felicidade (utilidade) é atingido quando as pessoas são capazes de concretizar suas preferências na máxima medida possível.

É necessário, quando se trata de utilitarismo político, que esses arranjos institucionais básicos da sociedade devem estar “orientados a buscar a máxima utilidade social possível” (SAVARIS, 2011, p. 34). Ou seja, sustenta-se que o utilitarismo social prescreve reformas institucionais que visam o princípio da máxima felicidade do maior número de pessoas possíveis. Na concepção de John Rawls (2001, p. 43), a concepção marcante da visão utilitarista da justiça é a de que não importa, a não ser indiretamente, o modo como à totalidade das satisfações é distribuída e nem sua forma, importando, apenas, a maior satisfação possível.

Dessa forma, entende-se que quando há maximização da satisfação da maioria perante uma minoria, não há motivos para que esses maiores ganhos não compensem as possíveis perdas. Mais do que isso, é importante conscientizar a real aplicação que esse movimento reflete no universo fático-jurídico da pós-modernidade, pois se a pretensão maior é maximizar as utilidades de uma maioria, não há razão para que o talhamento dos Direitos Fundamentais de uma minoria não possa ser justificado moralmente em prol desta.

A sociedade, tal como o indivíduo poderá fazer sacrifícios pessoais para almejar vantagem maior ao final, devendo ser arranjada, institucionalmente, de modo a obter o grau máximo de utilidade, mesmo que para tanto fosse necessário o "sacrifício" de direitos consagrados. Ou seja, a ética utilitarista defende a promoção do bem-estar social geral, mesmo que para isso seja necessário o detrimento de Direitos Fundamentais. Na concepção de José AntonioSavaris (2011, p. 35), “o utilitarismo respalda as medidas que são adotadas com o objetivo de preservação de um interesse social geral, fundado em critérios agregadores de desenvolvimento (renda per capita nacional, PIB, superávits)", não se importando com a (in)consequência para o sistema constitucional vivenciado (e conquistado).

Há dois eixos críticos dirigidos ao utilitarismo: Em um primeiro momento, dirige-se a atuação do judiciário voltado absolutamente em resultados considerados sociais e economicamente mais úteis, que considera o Direito como meio de consecução para possibilitar certos fins. A segunda crítica - essa mais voltada para nosso estudo - é 
realizada à atitude funcional utilitarista na realização do Direito Previdenciário proporcionado pela racionalidade instrumental assumida pelo pensamento jurídico.

Na visão de AntonioCastanheira Neves (1993, p. 36), se o discurso teórico tem como objetivo a realidade - no presente caso, financeira - e essa realidade é avaliada de modo técnico (meio-fim), "considera-se a verdade objetiva na perspectiva da adequação funcional ou aptidão instrumental da realidade". Ou seja, um discurso instrumental, cuja realidade é a eficácia.

Sendo apenas aplicado o discurso instrumental, a consequência para concreta realização do Direito paira apenas em termos sociais-políticos, eliminando a autonomia e a especificidade da normatividade jurídica. Para a realização do Direito, a essência se encontra nos fundamentos normativos (artigo 29, II, da Lei 8.213/91), e não nos efeitos empíricos ou impactos de determinado direito sobre metas econômicas.

Nesse diapasão, o acordo efetuado na Ação Civil Pública $n^{\circ}$ 000232059.2012.4.03.6183pelo MPF, pelo SINDNAPI e pelo INSS pode ser caracterizado, além de uma ética utilitarista, como uma proposta a noção do ponto "Óptimo de Pareto"5. Ou seja, tentou-se buscar a felicidade geral, contudo, foi obrigado a invadir a esfera de Direitos Fundamentais Sociais de um determinado grupo.

O acordo efetuado teve como principal núcleo a minimização dos prejuízos que o INSS viria a ter - e consequentemente todos que dependem e dependerão dele - se esses pagamentos fossem efetuados todos de forma simultânea. Contudo, para isso, foi aceito um acordo prejudicial aos Direitos Sociais dos beneficiários (minoria) envolvidos.

Nota-se, fundamentalmente, que a partir do momento que uma instituição social é pautada pela ética utilitarista, ela implica a submissão dos Direitos Individuais e Fundamentais à satisfação de contentos majoritários, como foi o caso do acordo em estudo. Os benefícios previdenciários, dada sua inerência à dignidade da pessoa humana, não podem ser pautados por uma lógica utilitarista em que a avaliação do impacto econômico das decisões guarda "preponderância sobre o exame das implicações humanas - sobre as pessoas afetadas - delas advindas" (SAVARIS, 2011, p. 198).

\footnotetext{
${ }^{5}$ Trata-se de um conceito desenvolvido por Vilfredo Pareto em que um resultado seria ideal se não pudesse mais ser melhorado ou quando não se puder melhorar um dos fatores sem o detrimento de outro fator participante.
} 


\section{Garantia dos benefícios previdenciários versus a reserva do possível}

A questão dos direitos fundamentais, principalmente o que tange os direitos sociais, seja quanto sua promoção ou sua ampliação, ainda possuem celeumas a serem discutidas, principalmente quanto às limitações orçamentárias do Estado.

Uma definição material dos direitos sociais, característica de um Estado de Direito Social, independentemente da diferenciação de positivação constitucional, pode ser: um direito a um mínimo existencial; direito à saúde; à habitação; segurança social; ao trabalho e à educação. Percebem-se duas características essenciais dos direitos sociais no rol acima: (a) todos possuem ou um núcleo econômico, ou social ou cultural cujos são indispensáveis a uma vida digna, porém (b) com a minudência de se tratar de bens custosos que só serão efetivados se o ser humano tiver condições financeiras próprias ou pelas instituições em que se integrem ou, ainda, se houver uma prestação estatal adequada (NOVAIS, 2010, p. 41).

As pressões sociais ocorridas na modernidade determinaram uma mudança na concepção de proteção estatal vigente à época, quando houve maior exigência na participação ativa do Estado, especialmente quando o salário passou a ser a principal fonte de subsistência dos membros da sociedade. A devida tutela em face dos trabalhadores contra possíveis malefícios sociais como, por exemplo, a velhice, acidentes, doenças, começa a ganhar estrutura. Da mesma forma que seria impossível a completa prestação do direito libertário da vida sem a prestação estatal em políticas públicas de saúde, seria impossível a prestação constitucional de amparo ao idoso (artigo 230) sem um sistema viável de previdência social.

Contudo, em posição diversa da jusfundamentabilidade dos Direitos Sociais, há doutrina que entende ser impossível a compreensão desses por necessitarem de concretização legislativa, afastando-se, assim, da noção de Direitos Fundamentais. Mas como analisado alhures, essa concepção já foi desmantelada. Entretanto, essa mesma corrente traz questões não apenas de jusfundamentabilidade, mas também políticaconstitucional, como é o caso do limite orçamentário na concretização dos Direitos Sociais: a reserva do possível.

Os direitos sociais pressupõem um facere por parte do destinatário da norma jusfundamental, o que gera, além disso, reflexos orçamentários, econômicos e financeiros (SARLET, 2013, p. 545). Em vista tanto da dimensão fática, quanto do viés jurídico, na concepção de Ingo Sarlet (2013, p. 547), passou-se a sustentar que os 
direitos sociais a prestação material estariam sob a "reserva do possível", caracterizada por uma tríplice dimensão:

a) a real disponibilidade fática de recursos para efetivação dos direitos sociais; b) a disponibilidade jurídica dos recursos materiais e humanos, que guarda conexão com a distribuição das receitas e competências tributárias, orçamentárias, legislativas e administrativas e, em países como o Brasil, ainda reclama equacionamento em termos de sistema federativo; c) e o problema da proporcionalidade da prestação, em especial quanto à sua exigibilidade e razoabilidade, no que concerne à perspectiva própria e peculiar do titular do direito (SARLET, 2013, p. 547).

Nesse diapasão, constata-se uma tendência por parte da doutrina e da jurisprudência em reconhecer a exigibilidade dos Direitos Sociais a prestações, tanto como direitos originários a prestações quanto direitos derivados, privilegiando, todavia, especialmente no primeiro caso, prestações indispensáveis à sobrevivência digna da pessoa.

Entretanto, ainda que haja manobras políticas para delimitar o escopo da eficácia dos Direitos Sociais, isso não significa que a sua jusfundamentalidade seja excluída. Caso houvesse essa negação, seria o mesmo que negar a eficácia normativa dos princípios jurídicos.

A necessidade de complementação da ordem constituição social pelo legislador extravagante, não afasta sua jusfundamentabilidade. Caso contrário, estaria "prerrogando" o Legislador em delimitar as intenções do Constituinte (DERBLI, 2007, p. 105). A regulação infraconstitucional é um dever do Legislador para com o Constituinte, não devendo ser um mensurador da jusfundamentalidade dos Direitos Sociais.

\subsection{Reserva do possível e o escopo previdenciário}

Como já referido, a Previdência Social tem uma função de superioridade protetiva frente os demais mecanismos sociais, pois esse direito tem uma sistemática própria e está estritamente vinculado ao equilíbrio financeiro e atuarial, atendendo ao desejo da vida digna em respeito às limitações econômicas inerentes ao Estado PósSocial.

Reconhecer a Previdência Social como um Direito Fundamental Social é algo inerente à Dignidade da Pessoa Humana e a concretização do Estado Democrático de 
Direito. Na sociedade hodierna é impossível viver de forma digna sem um sistema de benefícios previdenciário consolidado. Nas palavras de Paulo Bonavides (2009, p. 566) pode-se dizer que a Previdência Social seria uma garantia institucional, haja vista superar a solidão individualista da concepção clássica dos Direitos Fundamentais, já que suas diretrizes e existência se dão com base na solidariedade entre seus participantes.

A jusfundamentalidade da Previdência Social se dá na sua garantia institucional, e não em cada benefício em separado. Seria incorreto dividir o reconhecimento de um Direito Fundamental ao benefício por invalidez e um Direito Fundamental à aposentadoria rural. A sociedade brasileira só poderá estabelecer uma isonomia e concretização das liberdades subjetivas a partir da mantença do sistema previdenciário, pois ela é o garante dos contribuintes quando ocorrer algum imprevisto.

Ademais, é um ônus social a garantia da vida digna para com todos. A Dignidade da Pessoa Humana não é somente prerrogativa do Estado, mas, também, um dever entre particulares. As vantagens do sistema solidário da Previdência Social para com o princípio da Dignidade da Pessoa Humana é um exemplo real e latente na sociedade pós-moderna. Exige-se daí, os meios necessários para obtenção de uma existência digna.

Nesse contexto que a Previdência Social, em contento com outras ações político-sociais, não se limita ao mínimo vital, mas deve atender, além do mínimo existencial, os riscos sociais da crescente pós-modernidade, com a devida proteção e inclusão social efetiva.

Contudo, a problemática a ser enfrentada pela Previdência Social é resguardada na questão atuarial. A Constituição em seu artigo 201, caput, dispõe que o sistema previdenciário brasileiro deve buscar o equilíbrio financeiro e atuarial. Ocorre que, na realidade, o termo atuarial não faz parte da realidade desse sistema. O que se vê é uma desproporcional atuação do gestor do sistema na alteração da equação atuarial previdenciária, ou seja, aumenta-se e diminuem-se as contribuições/benefícios sem se importar com as consequências futuras, sendo que deveria ocorrer o "balanceamento em longo prazo entre o financiamento dimensionado incialmente e as prestações a serem concedidas, com base na sinistralidade esperada"6. Se há um aumento na prestação devida, deveria haver um aumento no valor do benefício ou, ao menos, uma justificativa

\footnotetext{
6 IBRAHIM, Fábio Zambitte. A Previdência Social como Direito Fundamental. Disponível em <http://www.impetus.com.br/noticia/download/21/a-previdencia-social-como-direito-fundamental>. Acesso em 05/05/2015.
} 
atuarial para o não aumento como, por exemplo, o aumento da expectativa de vida. Conquanto, isso não ocorre em nossa realidade.

O que ocorre, além da ausência de um controle atuarial pelo sistema previdenciário, é o problema da discricionariedade da Administração Pública sobre a fixação de índices, eis que ela se ocupa, apenas, da existência de recursos orçamentários naquele determinado exercício, sem a devida preocupação da criação da fonte de custeio e da manutenção da prestação majorada dos futuros exercícios ${ }^{7}$, visto que a previdência tem preponderância em prestações continuadas.

Na concepção de Fábio Zambitte Ibrahim, o contexto pós-social, além de reconhecer a jusfundamentalidade do seguro social, impõe o sopesamento das limitações financeiras, expondo a necessidade da Previdência se ater na "reserva do possível atuarial", haja vista que para o sistema ser efetivamente equilibrado, o plano de benefícios deve ater-se, rigorosamente, ao plano de custeio ${ }^{8}$. Há, portanto, no contexto do Seguro Social, uma tridimensionalidade da concepção de reserva do possível: além das clássicas acepções fática (recursos efetivamente existentes) e jurídica (previsão orçamentária), deve ser aliada a percepção atuarial.

Há, em contrapartida a fundamentação acima, uma situação periclitante: a questão político-social da desvinculação das receitas de contribuições sociais, conforme veiculada pelo artigo 76 do Ato dasDisposições Constitucionais Transitórias- ADCT, que desvincula, até 31 de dezembrode 2015, $20 \%$ da arrecadação de contribuições atreladas à Seguridade Social, podendoser aplicada em outras despesas.

A desvinculação tem como fundamento a manutenção do equilíbrio das contas do Governo Federal e também a garantia de maior flexibilização dos gastos públicos federais e, em especial, possibilitar o pagamento de serviços da dívida externa (CALCIOLARI, p. 2009, p. 56).

Eis a questão nuclear a ser enfrentada: Se há possibilidade da desvinculação, há verba suficiente para resguardar as despesas da Seguridade Social, incluindo a Previdência.

As contribuições sociais são mecanismos garantidores da efetividade dos direitos fundamentais, em especial os sociais. Os mecanismos que as desvinculam dessas finalidades devem ser acoimados de inconstitucionalidade, por prejudicar a 
efetividade desses direitos, eis que afastam sua aplicabilidade fática, impossibilitando a implementação, visto não haver o aporte financeiro necessário.

Esse mecanismo de flexibilização é utilizadocom o fulcro de retirar "parcelas constitucionalmente destinadas à efetivação dos direitos sociais para cobrir os encargos das dívidas ou as altas taxas de juros. Se verificamos a ampliação da arrecadação para fins sociais, por outro, apontamos sua desvinculação para utilização diversa da constitucionalmente imposta" (CALCIOLARI, 2009, p. 64).

A aplicação da reserva do possível no sistema previdenciário, por maior que seja a necessidade na sua visão tridimensional - financeiro, orçamentário e atuarial - e a estrita vinculação entre custeio e benefício, entra em contradição e esvazia ainda mais o fundo previdenciário, visto a ausência de confiança dos seus contribuintes para com o sistema, algo que é salutar e necessário para sua mantença. Ou seja, se houvesse uma vinculação efetiva das receitas das contribuições sociais em favor da seguridade, o sistema previdenciário seria superavitário. Há um flagrante desrespeito à Constituição Federal, conforme defende o artigo 195, $\S 2^{\circ}$.

Além do flagrante desrespeito à Constituição, a autarquia gerenciadora da Previdência Social não pode alegar dificuldades financeiras para o descumprimento do pagamento dos benefícios devidos cujos requisitos de acesso já foram preenchidos pelo segurado (ROCHA, 2014, p. 114). No caso da revisão objeto do acordo formulado na Ação Civil Pública citada, estabeleceu-se um vínculo entre a capacidade contributiva e as prestações previdenciárias ofertadas e asseguradas em lei, devendo, pois, haver o asseguramento e pagamento imediato das prestações devidas, pois já foi estabelecido o pagamento dos requisitos para concessão do benefício.

Contudo, se houvesse uma séria crise na Seguridade Social, qual seria a saída? Negar-se-ia os Direitos sociais da saúde, previdência e assistência? Quando há um conflito entre a realidade factual e a Constituição, esta não pode ser considerada a parte mais fraca. Ademais, nossa própria Carta Magna instituiu remédios para um possível desiquilíbrio entre os recursos orçamentários e as necessidades de natureza social, ofertando o artigo 195, $\S 4^{\circ}$ e o artigo 250 como pressuposto realizáveis. O primeiro possibilita outras instituições serem fontes destinadas a garantir a manutenção da Seguridade e a outra possibilita que a União, por fundo integrado de bens e ativos de qualquer natureza, garantam os recursos para mantença do pagamento dos benefícios.

Quando se parte do pressuposto que o fim consequencial do sistema de Previdência Social é alcançar a eficiência econômica, quando deixa-se de perceber que 
a eficiência não é um fim em si mesmo, a Previdência Social deixa de resguardar o cidadão e faz com que esse, mesmo ao custo de sua vida, fortaleça o Estado para o alcance da maior disponibilidade possível de recursos financeiros, maior utilidade e maior segurança financeira.

Medir as consequências econômicas é "emprestar importância à eficiência”, o qual tem como sequelas, em relação ao Direito Previdenciário, a) o esquecimento dos fundamentos éticos correlacionados com a proteção do beneficiário, e b) o prestigio ao resguardo máximo das riquezas do sistema em detrimento do indivíduo e suas necessidades (SAVARIS, 2011, p, 213).

\section{CONSIDERAÇÕES FINAIS}

A constante luta contra os riscos sociais, consequência da crescente economia e da desregulada gestão dos métodos de economia coletiva, exigiu não apenas a proteção estatal, mas exigiu que o próprio Estado assumisse a implementação, organização e a gerência da proteção social, cuja expressão por ser definida pela Seguridade Social.

A Previdência Social é um direito formal e materialmente fundamental, visto sua implementação direta pela Constituição Federal de 1988, em seu artigo $6^{\circ}$, quanto por força das normas internacionais que o Brasil é signatário (artigo $5^{\circ}, \S 2^{\circ}$ ) como, por exemplo, a Declaração Universal dos Direitos do Homem, em seu artigo 22, e a Declaração Americana dos Direitos e Deveres do Homem em seu artigo XVI.

Quando é sujeitada a Previdência Social à ética utilitarista estamos indo de encontro à concretização da Dignidade da Pessoa Humana, pois, além se tratar de um sistema contributivo, em que o beneficiário necessita preencher os requisitos em lei para ter direito à concessão de um benefício, a Previdência é o único meio de subsistência de quem depende dela, haja vista seu restritivo e rígido campo de concessão.

Quando deparado com o acordo firmado na Ação Civil Pública nº 000232059.2012.4.03.618, verifica-se a extrema preocupação que a autarquia tem em apenas aumentar e desonerar sua tabela orçamentária.

Os contribuintes não podem ser prejudicados por motivos de má gerência no Poder Público, visto que, além dos contribuintes preencherem todos os requisitos para concessão do benefício, não houve nenhuma reposição quantos os valores não pagos. Ou seja, se são valores enquadrados na reserva atuarial, pago pelos contribuintes, não devolvidos no momento da concessão (1999 a 2009), esses valores deveriam estar 
disponível para o pagamento na hora da revisão. Além de ilegal, é injusto com quem contribui com um sistema e na hora que mais precisa dele, as verbas estão indisponíveis com a justificativa de limite orçamentário.

Ademais, a questão da desvinculação das contribuições sociais é outro fator peculiar. As contribuições sociais são mecanismos garantidores da efetividade dos direitos fundamentais, em especial os sociais. Os mecanismos que as desvinculam dessas finalidades devem ser acoimados de inconstitucionalidade, por prejudicar a efetividade desses direitos, eis que afastam sua aplicabilidade fática, impossibilitando a implementação, visto não haver o aporte financeiro necessário.

Quando o fim consequencial do sistema de Previdência Social é almejar a eficiência econômica e a utilidade geral, quando deixa de perceber que a eficiência não é um fim em si mesmo, a Previdência Social deixa de proteger o cidadão e faz com que esse, mesmo ao custo de sua dignidade (ou vida), fortaleça o Estado para o alcance da maior disponibilidade possível de recursos financeiros, maior utilidade e maior segurança financeira.

\section{REFERÊNCIAS BIBLIOGRÁFICAS}

BALERA, Wagner. A Seguridade Social na Constituição de 1988, São Paulo: LTr, 2000.

BERBEL, Fabio Lopes Vilela. Teoria geral da previdência social. São Paulo: QuartierLatin, 2005.

BITENCOURT NETO, Eurico. O direito ao mínimo para uma existência digna. Porto Alegre: Livraria do Advogado Editora, 2010.

BONAVIDES, Paulo. Curso de direito constitucional. 24 ed. atual. eampl. São Paulo: Malheiros Editores Ltda, 2009.

CALCIOLARI, Ricardo Pires. A crise de efetividade dos direitos sociais e a desvinculação de receitas. ROCHA, Daniel Machado da; SAVARIS, José Antônio (Coord.). Curso de especialização em direito previdenciário - vol. 3.Curitiba: Juruá, 2009. 35-72 p.

CORREIA, Marcus Orione Gonçalves. Comentários ao art. 194. CANOTILHO, J. J. Gomes; MENDES, Gilmar F.; SARLET, Ingo W.; STRECK, Lenio L. (Coords.). Comentários à Constituição do Brasil. São Paulo: Saraiva/Almedina, 2013, p. 1902 1907. 
DERBLI, Felipe. O princípio da proibição de retrocesso social na Constituição de 1988. Rio de Janeiro: Renovar, 2007.

IBRAHIM, Fábio Zambitte. A Previdência Social como Direito Fundamental. Disponível em < http://www.impetus.com.br/noticia/download/21/a-previdencia-socialcomo-direito-fundamental>. Acesso em 05/05/2015.

KATO, Cesar Augusto; KAMPA, Rose. Direito constitucional à prova e a perícia médica previdenciária no Juizado Especial Federal. SAVARIS, José Antonio. Curso de Perícia Judicial Previdenciária. São Paulo: Conceito Editorial, 2011.

LEDUR, José Felipe. Direitos fundamentais sociais: efetivação no âmbito da democracia participativa. Porto Alegre: Livraria do Advogado Editora, 2009.

Ministério da Previdência Social. Disponível em: < http://agencia.previdencia.gov.br/eaps/servico/414>. Acesso em 10/05/2015.

Ministério da Previdência Social. Disponível em: < http://www.previdencia.gov.br/noticias/beneficios-inss-fecha-acordo-para-pagamentode-revisao-de-beneficios-por-incapacidade/> . Acesso em 10/05/2015.

NEVES, Antonio Castanheira. Metodologia jurídica: problemas fundamentais. Coimbra: Coimbra, 1993.

NOVAIS, Jorge Reis. Direitos Sociais - Teoria Jurídica dos Direitos Sociais enquanto Direitos Fundamentais. Coimbra: Coimbra editora, 2010.

POSNER, Richard A. A economia da justiça. Tradução de Evandro Ferreira e Silva; revisão da tradução Aníbal Mari. São Paulo: WMF Martins Fontes, 2010.

ROCHA, Daniel Machado da; BALTAZAR JUNIOR, José Paulo. Comentários à lei de benefícios da previdência social. 11. ed. rev. atual. Porto Alegre: Livraria do Advogado Editora: Esmafe, 2012.

ROCHA, Daniel Machado da. O direito fundamental à previdência social na perspectiva dos princípios constitucionais diretivos do sistema previdenciário brasileiro. Porto Alegre: Livraria do Advogado Editora, 2014.

SARLET, Ingo Wolfgang. Comentários ao artigo $6^{\circ}$. CANOTILHO, J. J. Gomes; MENDES, Gilmar F.; ; STRECK, Lenio L. (Coords.). Comentários à Constituição do Brasil. São Paulo: Saraiva/Almedina, 2013, p. 533-548.

SAVARIS, José Antonio. Noções jurídicas fundamentais sobre os benefícios previdenciários por incapacidade. (org.). Curso de Perícia Judicial Previdenciária. São Paulo: Conceito Editorial, 2011. 
SAVARIS, José Antonio. Uma Teoria da Decisão Judicial da Previdência Social:

Contributo para Superação da Prática Utilitarista. Florianópolis: Conceito Editorial, 2011. 